68. Isalkar U. Pune: Radiologists demand amendment to PCPNDT Act Healthworld (From the Economic Times). 2015 Dec 9 [cited 2018 May 11]. Available from: https://health.economictimes.indiatimes.com/ news/industry/pune-radiologists-demand-amendment-to-pcpndtact/50109294.

69. Mascarenhas A. IMA to move SC against PCPNDT Act provisions Indian Express. 2014 Apr 8[cited 2018 May 11]. Available from: http:// indianexpress.com/article/india/india-others/ima-to-move-sc-againstpcpndt-act-provisions-2/.

70. Indian Radiological and Imaging Association vs. Union of India (W.P. (C) 6968/2011). High Court of Delhi at New Delhi; 2016.

71. Masand P.'Silent Observer' sonography model for state? Times of India. 2011 Jan 30 [cited 2018 May 11]. Available from: https://timesofindia. indiatimes.com/city/mumbai/Silent-observer-sonography-model-for- state/articleshow/7387461.cms.

72. Kore SS. Understand the Silent Observer Device SIOB. Waranahealth com. 2011 Dec 14 [cited 2018 May 11]. Available from: http://www. waranahealth.com/understand-the-silent-observer-device-siob.aspx.

73. Purandare V. Tracking devices on songraphy machines. Asian Age; 2017 Aug 22 [cited 2018 May 11]. Available from: http://www.asianage.com/ metros/mumbai/220817/tracking-devices-on-sonography-machines. html.

74. Srivastava K. Exclusive: Maharashtra government's Silent Observer can do little to save girl child. DNA India. Updated 2011 Sep 19 [cited 2018 May 11]. Available from: http://www.dnaindia.com/mumbai/reportexclusive-maharashtra-government-s-silent-observer-can-do-little-tosave-girl-child-1588899.

\title{
Cooperation in confidential withholding of HIV status from partners of sexually-active patients: A role for organisational moral agency
}

\section{PETER A DEPERGOLA II}

\section{Abstract}

An increasingly blurred understanding of the conditions under which clinicians may withhold HIV seropositive status from partners of patients who are sexually active and who do not intend to disclose suggests a critical need to revisit the relationship between the principle of confidentiality, the moral and legal duties to warn at-risk third parties, and the organisational ethics surrounding licit cooperation with wrongdoing in the effort to uphold professional moral responsibility. This essay grounds its argument in two, straightforward premises: (i) the ethical principle of cooperation is an indispensable measure of the moral licitness of instances of complicity with wrongdoing; (ii) some instances of material organisational complicity vis-à-vis confidential withholdings of HIV seropositive status from partners of sexually active patients both meet and successfully employ the standards of the ethical principle of cooperation. Drawing from this syllogism, the essay argues that, in Type II cases, healthcare organisations may (initially and on certain conditions) materially cooperate in withholding the HIV seropositive status of patients from partners with whom patients are sexually active, and to whom patients do not intend to disclose HIV seropositive status, in the effort to honour professional obligations of privacy, confidentiality, and fidelity in a manner that is both legally licit and morally justifiable.

\footnotetext{
Author: Peter A DePergola II (drpeterdepergola@gmail.com), Assistant Professor of Medicine, University of Massachusetts Medical School, Worcester, MA, USA; Assistant Professor of Medicial Humanities, College of Our Lady of the Elms, Chicopee, MA, USA.

To cite: DePergola PA II. Cooperation in confidential withholding of HIV status from partners of sexually-active patients: A role for organisational moral agency. Indian J Med Ethics. 2019 Jan-Mar;4(1)NS: 45-9. DOI:10.20529/ IJME.2018.080.

Published online on October 29, 2018

OIndian Journal of Medical Ethics 2018
}

\section{Introduction}

For the past two decades, guidelines of the United States Public Health Service (1) have recommended that individuals infected with human immunodeficiency virus (HIV) notify their sexual partners (2) ${ }^{1}$. Failure to disclose HIV seropositive status has been condemned as a moral and legal offence subject to both civil liability and criminal prosecution (3). In order to shield individuals living with HIV from disadvantages that may inhibit them from undergoing testing or from transparent disclosure of HIV status, their rights to privacy must be protected. This necessity underscores and invigorates the argument that clinicians, who have a (prima facie) moral obligation respect patients' confidentiality, should be strictly bound not to disclose the HIV seropositive status of patients without their consent or without other legal justification. However, competing with the need to safeguard the privacy of individuals living with HIV is the public health necessity of curbing the spread HIV (1). The drive to halt the spread of the pandemic, some argue, requires the adoption of measures such as informing the sexual partners of individuals whose HIV seropositive status has been ascertained through testing (4). Hence, such notification would enable uninfected partners to protect themselves against HIV infection, either by avoiding unprotected sex with infected partners or by abstaining from sexual intercourse with them. For some classes of medical professionals, striking a balance between these competing private and public health interests can breed serious ethical dilemmas on both professional and organisational levels (5).

An increasingly blurred understanding of the conditions under which clinicians may legitimately withhold HIV seropositive status from partners of patients who are sexually active and who do not intend to disclose suggests a critical need to revisit the relationship between the notion of confidentiality, the moral and legal duties to warn atrisk third parties, and the organisational ethics surrounding licit cooperation with wrongdoing in the effort to uphold 
professional moral responsibility. This essay grounds its argument in two, straightforward premises: (i) the ethical principle of cooperation is an indispensable measure of the moral licitness of instances of complicity with wrongdoing; (ii) some instances of material organisational complicity visà-vis confidential withholding of HIV seropositive status from partners of sexually active patients both meet and employ the standards of the ethical principle of cooperation. Drawing from this syllogism, this essay posits the argument that, in Type II cases, healthcare organisations may (initially and on certain conditions) materially cooperate in withholding the HIV seropositive status of patients from partners with whom patients are sexually active, and to whom patients do not intend to disclose HIV seropositive status. This is part of the effort to honour the professional obligations of privacy, confidentiality, and fidelity in a manner that is both legally licit and morally justifiable.

\section{The professional ethics of treating infidelity: Organisational cooperation in healthcare The ontology of cooperation}

The ethical principle of cooperation holds that directly intended cooperation in an action independently deemed morally illicit is unjustifiable, whereas indirectly intended cooperation in the unavoidable circumstances of such an action may be morally justifiable. The purpose of the principle is to clarify how licit moral decisions can be made even where complicity with wrongdoing is present $(6)^{2}$. Unlike the principle of toleration proposed by Augustine and Aquinas, ${ }^{3}$ the principle of cooperation explicitly implies that one's actions are inextricably intertwined with the wrong actions of another. The cooperation with another's wrongdoing can be deemed either moral (ie, "formal" and, hence, illicit) or physical (ie, "material" and, hence, potentially licit) (6).

The principle of cooperation can be successfully applied in circumstances of complicity only insofar as the cooperator's action is either morally good or indifferent (licitly "material"), but not knowingly and intentionally wrong (illicitly "formal") $(7)^{4}$. Since the meaning of a moral action is determined by the object of the action, which clarifies whether an action is wrong in itself, apart from the individual intentions and contextual circumstances that surround it. This notion highlights two critical points inherent to the principle of cooperation: (i) that the principle is intended to address acts considered morally wrong regardless of the circumstances; (ii) that for cooperation to be justified the act of cooperating must not be wrong in itself (6) both of which underscore the principle's primary purpose of identifying the meaning of a moral action in the attempt to avoid moral culpability as determined by the distinction between illicit formal and licit material cooperation (6).

\section{Illicit formal cooperation}

Illicit formal cooperation involves the acknowledged and intentional consent of the cooperating agent to explicitly or implicitly participate in the wrongdoing of the principal agent. Hence, the critical factor in manifestations of formal cooperation is knowledge of the wrongful action and intention to participate in effecting it. Since acknowledged and intentional complicity in the wrongful actions of another is considered morally culpable, it cannot be justified. Illicit formal cooperation indicates that an individual intends a wrong action undertaken by another and cooperates, that is, actively participates, in it. Formal cooperation considered "explicit" exists to the extent that the cooperator clearly intends wrongdoing (6). Conversely, formal cooperation considered "implicit" exists when cooperation is immediately associated with (6), though not immediately participatory in, wrongdoing (6).

It is possible that individuals who believe themselves not to be formally cooperating with wrongdoing actually are. Someone may claim, for instance, that he or she is cooperating materially, and therefore licitly, in the wrongdoing of another when he or she is actually intending, approving, or desiring the activity. Take, for example, the clinician who, without duress (7) frequently forgets his or her clinical notes (which include sensitive medical information) in the hospital's public cafeteria. While these actions do not express explicit approval or intention, he or she is implicitly cooperating with wrongdoing, and formal cooperation, both implicit and explicit, is intrinsically wrong. On evidence of the clinician's consistent activity, no reason can be seen for the cooperator's conduct other than that he or she freely intends, or minimally approves, the activity (7).

\section{Licit material cooperation}

In contrast to illicit formal cooperation, licit material cooperation involves cooperation with the wrongdoing of another without in any way intending the wrongdoing. Hence, the cooperator neither agrees with nor shares the intention of the principal agent of the immoral action. This licit form of the principle is referred to as "mediate" material cooperation. Mediate material cooperation exists only insofar as the cooperator is sufficiently removed from the wrongful action of the principal agent. Such cooperation also requires that the cooperator's action must not be morally wrong in itself. In other words, the person involved in cooperation typically has the right, apart from the present circumstances, to perform the action in question (6). Thus, the cooperator should not participate in the wrongful action of the principal agent and should only be (unavoidably and, hence, inculpably) involved with the actions that may precede or follow the wrongful action (6).

Hence, immediate material cooperation characterises by action what implicit formal cooperation characterised by intention. As seen in the case above, the clinician who frequently forgets his or her notes in the cafeteria is implicitly formally cooperating with wrongdoing. The same activity can also be described as immediate material cooperation. Since both explicit and implicit formal cooperation is always wrong, immediate material cooperation is always wrong except when instances of duress distinguish it from formal cooperation (7). Here duress is understood as individual instance or collective extenuating circumstances that threaten to diminish the 
integrity of the individual or organization implicated. Applied in the current context, one example would include knowledge that an at-risk third party from whom HIV seropositive status is presently withheld is otherwise suicidal and may not be able to emotionally appropriate the disclosure (7). Nevertheless, a legitimate application of the principle of cooperation requires that all realistic and feasible options are explored to distance individuals and organisations from the wrongdoing of another (7).

\section{The complexity of confidentiality and the duty to warn}

\section{Balancing patient confidentiality and public good}

Since the first cases of HIV were reported in 1981, the epidemic has posed a daunting challenge to public health officials, policymakers, and the public at large. As of 2004, approximately forty million people were living with HIV. In the same year, the HIV epidemic claimed more than three million lives, and close to five million people acquired the virus. The dangerously rapid spread of HIV continues to expand worldwide, and its peculiarities stipulate discussions on issues of biomedical ethics. While such issues have already been thoroughly reviewed in the past, they now seem to acquire new meanings. The most complicated ethical and legal queries arise when the infected individual deliberately avoids informing the individual(s) of concern about the potential danger of contracting the infection (8). Hence, two powerful and conflicting organizational obligations arise. The first, concerning the obligation to respect the privacy of persons with HIV infection, has already been suggested. The Hippocratic oath admonishes clinicians to "tell no secret" obtained in the course of the therapeutic relationship (9), and the threat of stigma and discrimination has had a profound impact on the extent to which persons with HIV demand ironclad legal protections of confidentiality.

The second obligation is to promote the public good by informing individuals who may have been exposed to HIV. An international survey of AIDS legislation undertaken for the World Health Organization (WHO) found that thirty-three countries have specific confidentiality provisions related to HIV or AIDS (9). Hence, it is globally agreed that the public possesses a right to know if their sexual partners are infected with HIV, as well as a legitimate claim that they should not be exposed to significant danger without their knowledge or consent. Moreover, courts in North America have found clinicians liable for failure to inform third-parties of the risk of HIV infection (9). Thus, clinicians face dual organisational ethical loyalties and legal obligations: on the one hand, to maintain the confidence of patients; on the other, to reveal confidential information to persons at significant and imminent risk of contracting HIV infection (9).

\section{Moral duties to warn: The limits of confidentiality}

While compelling ethical reasons exist for protecting the privacy of individuals with HIV infection (9), it is relatively acceptable to argue that individuals have a general moral obligation to avoid harming or wronging others whenever possible. However, nonmaleficence is a general obligation that is not restricted to the transmission of HIV (10). What requires examination, then, is the question of whether this general obligation not to harm others implies specific obligations with regard to the possible transmission of HIV. What remains unclear in this context is whether the obligation to prevent transmission falls solely (or even largely) on those organisations and clinicians who care for those with HIV, or whether it comes down to either (i) the duty of those who are infected to be transparent, or (ii) everyone doing their respective best to protect themselves against transmission (11).

Some scholars argue for an absolute organisational moral duty to forewarn third parties of the HIV seropositive status of current sexual partners (11). Their claim is based on the attribution of high regard for third-party autonomy and informed consent. Their arguments typically concern the notion that forewarning allows those considering a future sexual relationship to make an informed, autonomous decision about whether or not to run the risk of infection (12). Charles Erin and John Harris contend that, once forewarned, the individual is only then free to make an autonomous decision and is responsible for his or her actions (11). Thus, individuals who become infected as a result of fully forewarned consensual sex are responsible for this harm; that is, the harm is self-inflicted, rather than the result of organisational complicity. Accordingly, HIV-infected individuals can be said to have fulfilled their moral obligations toward sexual partners, even in absence of explicit consent or intention to do so. However, even if this is accepted, it is not clear that an individual (third party) is necessarily being deceived when a sexual partner does not disclose his or her HIV seropositive status (11).

In this view, the organisational moral duty to forewarn does not take into account the significance of different levels of trust and expectation that may exist in a professional relationship (11). According to Erin and Harris, irrespective of how casual the sexual partner, the kind of activity being undertaken, and the gravity the risk, those who believe themselves to be HIV seropositive must forewarn. Yet this insistence on an absolute duty to disclose seems unnecessarily stringent, and, if the aim is to reduce the spread of infection, seems prone to fail, because even if observed it will result in some form of bland, universal disclaimer prior to sexual activity that, in an instance, very few are likely to take seriously. But the strength of this view lies in the intuition that there are at least some circumstances where disclosure is morally required, such as between long-term partners or those considering unprotected sex - perhaps in order to beget children, especially in Type II cases. So, while there may be solid ground for dismissing an absolute duty to disclose, it is ethically undesirable to move from this position to one where there is never an organisational moral obligation to disclose HIV seropositivity (11).

\section{Legal duties to warn: the Tarasoff case}

While there is no doubt that organisations permit clinicians to break confidentiality if maintaining it imposes danger for third parties, there remains a controversial debate, briefly delineated 
above, concerning whether clinicians have a legal and moral duty to do so. As previously indicated, some scholars believe that if the life and health of others are at risk, clinicians are not only allowed, in the best interests of the organisation, to break confidentiality, but are also morally obligated to do so $(11,12)$. Others believe, as previously noted, that all individuals possess an obligation to protect themselves through the use of prophylactic means in sexual intercourse (11). Of immediate concern to this essay, however, is the legal duty to warn (13), which has also been characterised as discriminating against HIV seropositive patients (11). There have been some interesting cases in the last fifteen years that deal with medical confidentiality and danger for third parties in different legal systems (14). In many countries, including Germany, Canada, New Zealand, and the UK (14) courts have rules that knowingly infecting someone with HIV constitutes a criminal offense (14). In addition to criminal prosecution, knowingly transmitting HIV may also create a civil liability (14).

The landmark legal case in America concerning the duty to warn is equal parts intriguing and tragic. In 1969, Prosenjit Poddar, a student at the University of California, fell in with love Tatiana Tarasoff, another student of the university. Following a brief relationship with her, the young man fell into depression and consulted a psychotherapist because he had fantasies of killing her. He even purchased a gun. The psychotherapist consulted a colleague and informed the campus police. After interviewing Poddar, the campus police concluded that there was no actual danger. Thus, neither Tarasoff nor her parents received any warning. Two months later, Poddar stabbed Tarasoff to death. Subsequently, the parents of Tarasoff sued the campus police, the health service, and the Regents of the University of California because neither they nor their daughter were informed of the danger. However, the trial court dismissed the case because it lacked a cause of action. Before Tarasoff, there was no duty for clinicians to inform others (14).

The plaintiffs filed an appeal and, in 1974, an appellate court ruled in its first Tarasoff-decision (Tarasoff $v$. the Regents of the University of California, also known as Tarasoff $l$ ) that the campus police were liable because they failed to warn the victim. In March 1975, the court granted a rehearing and changed the first decision. This rather unusual procedure was possibly provoked by a public discourse over the role of the police, but the second judgment, Tarasoff II, gives no reason for the rehearing. The second judgment released the police from all liability and focused on the therapist's duty to warn the victim (14). Interestingly, the court established a "duty to warn" in Tarasoff I, but replaced it in Tarasoff /I with the phrase "duty to protect." The first phrase is more accurate inasmuch as the lack of warning hit the mark on the matter of dispute. Also, clinicians cannot protect third parties at all times from dangerous patients, but warning will enable others to protect themselves (14). The conflict between patients' rights of confidentiality and the protection of others' bodies and lives is resolved by the Tarasoff II court with a now renowned dictum: "The protective privilege ends where the public peril begins." (14).

\section{Clinical manifestations of confidential withholdings of HIV status from patients' sexual partners}

The illicit formal cooperation of Type I cases

This essay defines "Type I" cases of organisational complicity with wrongdoing in the context of confidential withholding of HIV seropositive status in the following manner. Type I cases involve a clinician who, with organisational permission, views his or her moral obligations in the context of HIV seropositive disclosure in terms of the individual patient alone, and therefore ignores the potential harm that will be caused to the unaware third party. Such a clinician feels, and is organisationally supported in feeling, that the principles of privacy, confidentiality, and fidelity require him or her not to disclose HIV seropositive status without the explicit consent of his or her patient, who refuses to provide it. One reason for this is the belief that disclosure will engender a "trustless" atmosphere that will only drive HIV seropositive patients from seeking the medical attention they require (9).

According to the above description, the clinician (and, by immediate extension, the healthcare organisation) in Type I cases formally, and therefore illicitly, cooperates in wrongdoing by consciously permitting grave and imminent risk, and almost certain immediate harm, to the third party of his or her patient who is both sexually active and does not use prophylactic measures. Minimally, the positive actions of the clinician may be deciphered as immediate material cooperation, which, in the current context, is equally illicit. While the clinician may well believe his or her cooperation to be benevolent, it involves an explicit and immediate consent of will to the wrongdoing by intending to withhold the grave information and assisting in the wrongful action by taking no further steps to remedy it, including presumably, neglecting to counsel the patient on the importance of disclosure. Since the clinician directly intends to withhold information detrimental to the health of a patient's current sexual partner, he or she thereby shares moral responsibility for it. Such intentional complicity in the wrongdoing of another is morally culpable and, as such, can never be justified (6). Hence, this essay contends that, in Type I cases, the application of the principle of cooperation reveals formal organisational complicity with wrongdoing that cannot be ethically justified.

\section{The licit material cooperation of Type II cases}

This essay defines "Type II" cases of organisational complicity with wrongdoing in the context of confidential withholdings of HIV seropositive status from partners of patients in the following manner. Type II cases involve a clinician who, with organisational permission, views his or her moral obligations in the context of HIV seropositive disclosure in terms of both the immediate patient as well as the third party at risk, thus maintaining acute cognisance of the potential harm likely to be caused to the unaware third party. Generally speaking, such a clinician understands what the (prima facie) moral principles of privacy, confidentiality, and fidelity demand in such a circumstance. However, the clinician is also aware, both professionally and personally, that such moral duties also have limits. Hence, this clinician temporarily withholds his 
or her patient's HIV seropositive status from the at-risk third party only while, and on the condition that, he or she is (i) actively attempting to persuade the infected patient to cease endangering the third party, (ii) if persuasion fails, actively notifying the appropriate authorities, or (iii) if authorities take no action, actively notifying the endangered third party (10: pp 307-8).

According to the above description, the clinician (and, by immediate extension, the healthcare organisation) in Type II cases materially, and therefore licitly, cooperates in wrongdoing by taking concrete steps to avoid the imposition of grave and imminent risk, and almost certain immediate harm, on the third party of his or her patient. Simultaneously, he or she also remains loyal, through the providence of counsel, to the organisational principles of privacy, confidentiality, and fidelity. Here, the clinician is genuinely reluctant, and both explicitly and implicitly opposed, to cooperation with the immoral action of his or her patient. Hence, the clinician mediately cooperates inasmuch as he or she has taken measures to become removed from the patient's wrong action. Moreover, the clinician neither approves nor desires the wrongful action, and is only temporarily, and on certain conditions, willing to withhold his or her patient's HIV seropositive status (6). Hence, this essay contends that, in Type II cases, the application of the principle of cooperation reveals material organisational complicity with wrongdoing that, in turn, can be ethically justified.

\section{Conclusion}

From a public health perspective, both retrospective and prospective partner notification is critical to HIV prevention efforts $^{5}$. Partner notification must be seen not only as a public health strategy for notifying those already exposed, but also as an organisational opportunity for engaging and supporting HIV seropositive individuals in the lifelong process of negotiating their lives in the context of their infection. The incorporation of partner notification into the continuum of care exemplifies the integration of prevention and care for both HIV seropositive and HIV negative individuals. For infected individuals, this linkage integrates prevention into the care process (4). For uninfected individuals (ie, notified partners), the linkage integrates care into the process of prevention (4). A redefinition of the partner notification process, beginning at the organisational level, would therefore allow HIV seropositive individuals to be better supported in their ongoing processes of both disclosure and risk reduction (4).

\section{Notes}

1 For an excellent analysis of this issue in the Asian context, see Abraham S, Prasad J, Joseph A, Jacob KS, Confidentiality, partner notification, and HIV infection. Indian J Med Ethics. 2002 Jan-Mar;10(1):157-60.

2 The principle of cooperation was originally developed within the Catholic moral traditional and is typically attributed to Alphonsus Liguori. See Magill (6)

3 The principle of toleration contends that, when faced with serious moral evil, even in the presence of immediate and effective means to overcome it, accomplishing a higher good or obstructing a more serious evil may justify taking no action to prevent it. See Magill (6)

$4 \quad$ Some scholars have addressed the logical misnomer that the principle of cooperation is nothing more than the principle of double effect in disguise. The current essay contends that cooperation differs from double effect in (at least) two pertinent ways.First, double effect concerns those rare actions that, while possessive of a single (either morally right or neutral) object of activity, cause two effects, one of which is wrong. Cooperation, on the other hand, has two distinct objects of activity - the wrongdoer's and the cooperator's. The infrequent instances suitable for double effect thus pale in comparison to those fitting for cooperation, since cooperation can concern nearly all forms of human activity. Second, double effect addresses only one agent. Hence, if the agent does not act, the harmful effect will not occur. Cooperation, however, involves two agents, including one who already does, or will do, wrong independently of the cooperator. Therefore, unlike double effect, cooperation is not in the first place a permitting principle concerning whether one may act, but rather a guiding principle concerning how one should act in the face of wrongdoing. See (7)

For an excellent analysis of partner notification in the African context see: Trinh TT, Yatich N, Ngomoa R, McGrath CJ, Richardson BA, Sakr SR, Langat A, John-Stewart GC, Chung MH. Partner disclosure and early CD4 response among HIV-Infected adults initiating antiretroviral treatment in Nairobi Kenya," PLoS ONE.2016;11(10): 1-7,

\section{References}

1. United States Center for Disease Control. U.S. Public Health Service Recommendations for Human Immunodeficiency Virus Counseling and Voluntary Testing for Pregnant Women. Atlanta, GA: Center for Disease Control, 1995[cited 2018 Oct 21]. Available from: https://www. cdc.gov/mmwr/preview/mmwrhtml/00038277.htm

2 Stein MD, Freedberg KA, Sullivan LM, Savetsky J, Levenson SM, Hingson $\mathrm{R}$, Samet JH. Sexual ethics. Disclosure of HIV-positive status to partners. Arch Intern Med. 1998 Feb 9:158(3): 253-57.

3. World Health Organization. Guidelines on HIV Self-Testing and Partner Notification. Geneva, Switzerland: WHO Press, 2016 [cited 2018 Oct 20]. pp1-15. Available from https://www.who.int/hiv/pub/vct/hiv-selftesting-guidelines/en/

4. Golub SA, Indyk D. HIV-Infected individuals as partners in prevention: A redefinition of the partner notification process. Soc Work Health Care. 2006;42(3-4):225-35.

5. Odunsi B. Should caregivers be compelled to disclose patients' HIV infection to the patients' sex partners without consent? Stud Fam Plan 2007 Dec;38(4):297-306.

6. Magill G. A moral compass for cooperation with wrongdoing. In: Cafardi NP, ed. Voting and Holiness: Catholic perspectives on political participation. Mahwah, NJ: Paulist Press; 2012. pp135-42.

7. Keenan JF, Kopfensteiner TR. The principle of cooperation. Theologians explain material and formal cooperation. Health Progr. 1995 Apr;76 (3):23-7.

8. Sirinskiene A, Juskevicius J, Naberkovas A. Confidentiality and the duty to warn the third parties in the HIV/AIDS context. Med Etika Bioet. 2005 Spring-Summer;12 (1):2-6. [Lithuanian].

9. Gostin LO.Confidentiality vs the duty to warn:Ethical and legal dilemmas in the HIV epidemic. J Int Assoc Physicians AIDS Care. 1995 Sep; 1(8)33-4.

10. Beauchamp TL, Childress JF. Principles of biomedical ethics, 6th ed. New York: Oxford University Press, 2009.417 pp.

11. Bennett $R$, Draper H, Frith L. Ignorance is bliss? HIV and moral and legal duties to forewarn. J Med Ethics. 2000 Feb; 26(1): 9-15.

12. Ainslie DC. AIDS and sex: Is warning a moral obligation? Health Care Anal. 2002; 10(1):49-66.

13. Huprich SK, Fuller KM, Schneider RB. Divergent ethical perspectives on the duty-to-warn principle with HIV patients. Ethics Behav. 2003;13(3): 263-78.

14. Safken C, Frewer A.The duty to warn and clinical ethics: legal and ethical aspects of confidentiality and HIV/AIDS. HEC Forum. 2007 Dec; 19(4): 313-26. 